\title{
Global manifestations of a substorm onset observed by a multi-satellite and ground station network
}

\author{
H. Wang ${ }^{1, *}$, S. Y. Ma ${ }^{1}$, H. Lühr ${ }^{2}$, Z. X. Liu ${ }^{3}$, Z. Y. Pu ${ }^{4}$, C. P. Escoubet ${ }^{5}$, H. U. Frey ${ }^{6}$, H. Réme ${ }^{7}$, and P. Ritter ${ }^{2}$ \\ ${ }^{1}$ Inst. of Ionosphere and Magnetosphere, LOGEG, CNME; College of Electronic Informatics, Wuhan University, Wuhan \\ 430079, P. R. China \\ ${ }^{2}$ GeoForschungsZentrum Potsdam, Telegrafenberg 14473 Potsdam, Germany \\ ${ }^{3}$ Center for Space Science and Applied research, Chinese Academy of Sciences, Beijing, P. R. China \\ ${ }^{4}$ School of Earth and Space Science, Peking University, Beijing 100871, P. R. China \\ ${ }^{5}$ ESA/ESTEC (SCI-RSSD), Postbus 299, Keplerlaan 1, 2200 AG Noordwijk, The Netherlands \\ ${ }^{6}$ Space Sciences Laboratory, University of California, Berkeley, USA \\ ${ }^{7}$ CESR/CNRS, 31029 Toulouse, France \\ * now at: University of Michigan, 2455 Hayward Str., Ann Arbor, 48109, USA
}

Received: 1 July 2006 - Revised: 2 November 2006 - Accepted: 10 November 2006 - Published: 21 December 2006

\begin{abstract}
With a favorable constellation of spacecraft and ground stations, a study is made on the global manifestations of a substorm onset. The onset occurred simultaneously and conjugately in both hemispheres, confirmed by observations of the auroral breakup from IMAGE FUV-WIC and a sudden intensification of a westward electrojet from ground-based magnetometers. Concurrently with the onset, field-aligned and Hall currents in the auroral ionosphere are observed by CHAMP, which are consistent with the signature of a Harang discontinuity. Immediately after the onset a magnetic field dipolarization is clearly observed by Double Star TC-1, located near the central magnetotail and subsequently, by the Cluster quartet. The observations can be explained by a dawnward propagation of the substorm current wedge at a speed of about $300 \mathrm{~km} / \mathrm{s}$.
\end{abstract}

Keywords. Magnetospheric physics (Magneospheric configuration and dynamics) - Ionosphere (Auroral ionosphere)

\section{Introduction}

Magnetospheric substorms involve a repetitive process that dissipates electromagnetic energy of solar wind origin from the magnetosphere in the Earth's upper atmosphere. While much of the substorm morphology has been established, there are still a lot of controversies. The most important one concerns the exact physical conditions that initiate a substorm. There are many models which propose different

Correspondence to: $\mathrm{H}$. Wang

(whui@umich.edu) source locations in the magnetotail. For example, in the cross-tail current instability model (CCI), the onset occurs near the Earth $\left(6-10 R_{E}\right)$ (Lui, 1996). The CCI model postulates that plasma instabilities generate a cross-tail current disruption and a divergence into the ionosphere via fieldaligned currents (FACs), to form the substorm current wedge (SCW), which is considered as the substorm onset. After that, a rarefaction wave is launched tailward. This makes the midtail magnetic configuration even more stretched, thus favoring the occurrence of reconnection. Therefore, reconnection is started after the substorm onset. Alternatively, the near-Earth neutral line model (NENL) predicts that the substorm is initiated at a further distance $\left(>20 R_{E}\right)$ where reconnection takes place (Baker et al., 1996). The formation of the SCW and auroral intensification are considered to occur later, as secondary effects of the reconnection. The cause of the SCW could be explained by the braking of the fast earthward bursty bulge flows (Shiokawa et al., 1998) and the pressure gradient current induced by the flow braking (Birn et al., 1999). The CCI and NENL models can be distinguished by comparing the time when reconnection is observed at some distance in the tail with the time when the substorm onset is detected at near-Earth locations. If reconnection is observed first at some distance in the tail, the NENL model is more appropriate (Liou et al., 2002).

Because substorms have various influences on the Earth's magnetic field, magnetospheric and ionospheric currents, and auroral displays, all these phenomena should be studied using appropriate observational techniques. By ordering these phenomena, which take place in various regions and follow certain time sequences, one can distinguish the

Published by Copernicus GmbH on behalf of the European Geosciences Union. 


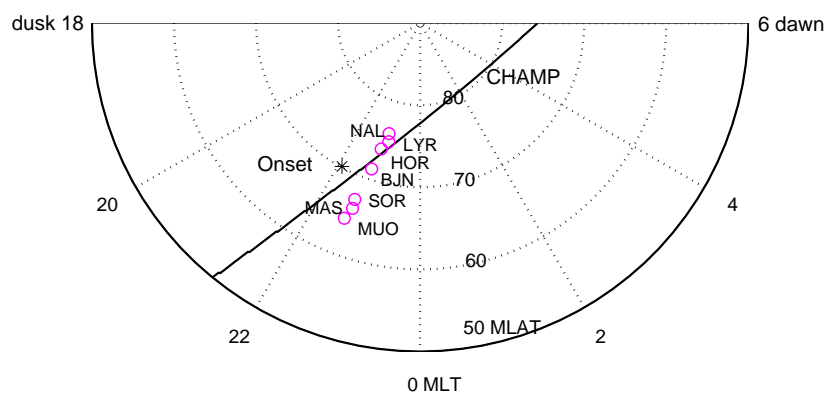

Fig. 1. CHAMP track in the ionosphere (line), conjugate substorm onset region (asterisk) and location of considered IMAGE magnetometer stations (circle) at onset time, 20:14 UT.

different substorm trigger mechanisms. The main causes for these controversies are probably the limitation in observations. During the last several decades, great progress has been achieved in observational techniques. The Cluster quartet, along with Double Star set up an excellent constellation for exploring the geospace. The latter two satellites, comprising TC-1 and TC-2, are part of the first scientific mission in China to study the Earth's magnetosphere (Liu et al., 2005). As a special feature, the magnetic local time of the Double Star coincides at apogee with that of the Cluster spacecraft. In a dedicated study Nakamura et al. (2005) used simultaneous observations of Cluster and Double Star to investigate the processes in the magnetotail associated with a dipolarization. By using a multi-point analysis technique they have determined that the propagation of the dipolarization was mainly dawnward. However, detailed ionospheric signatures related to this propagation of the disturbance are not included.

In this paper we study global manifestations of an isolated substorm onset involving both auroral and magnetotail processes, which may serve as critical tests for some of the controversies about substorms. The study makes use of coordinated observations from CHAMP and IMAGE, in addition to Cluster and Double Star, along with ground-based facilities of the magnetometer network IMAGE. These comprehensive data sets complement each other ideally in the auroral and magnetotail regions where substorm processes are involved.

\section{Observations}

The substorm under consideration took place on 2 September 2004, with its onset at 20:14 UT, as identified by IMAGE WIC observations. Shortly before the substorm onset the IMF underwent a northward turning at 20:00 UT, as observed by ACE (not shown here), which may be the interplanetary trigger for the substorm (Lyons, 1996). During the substorm the magnetic activity is quite low, with a min. SYM-H index of $-24 \mathrm{nT}$ and a max. $K_{p}$ of $1+$.

Figure 1 shows the north polar ionospheric footpaths of CHAMP, the conjugate location of the substorm auro-
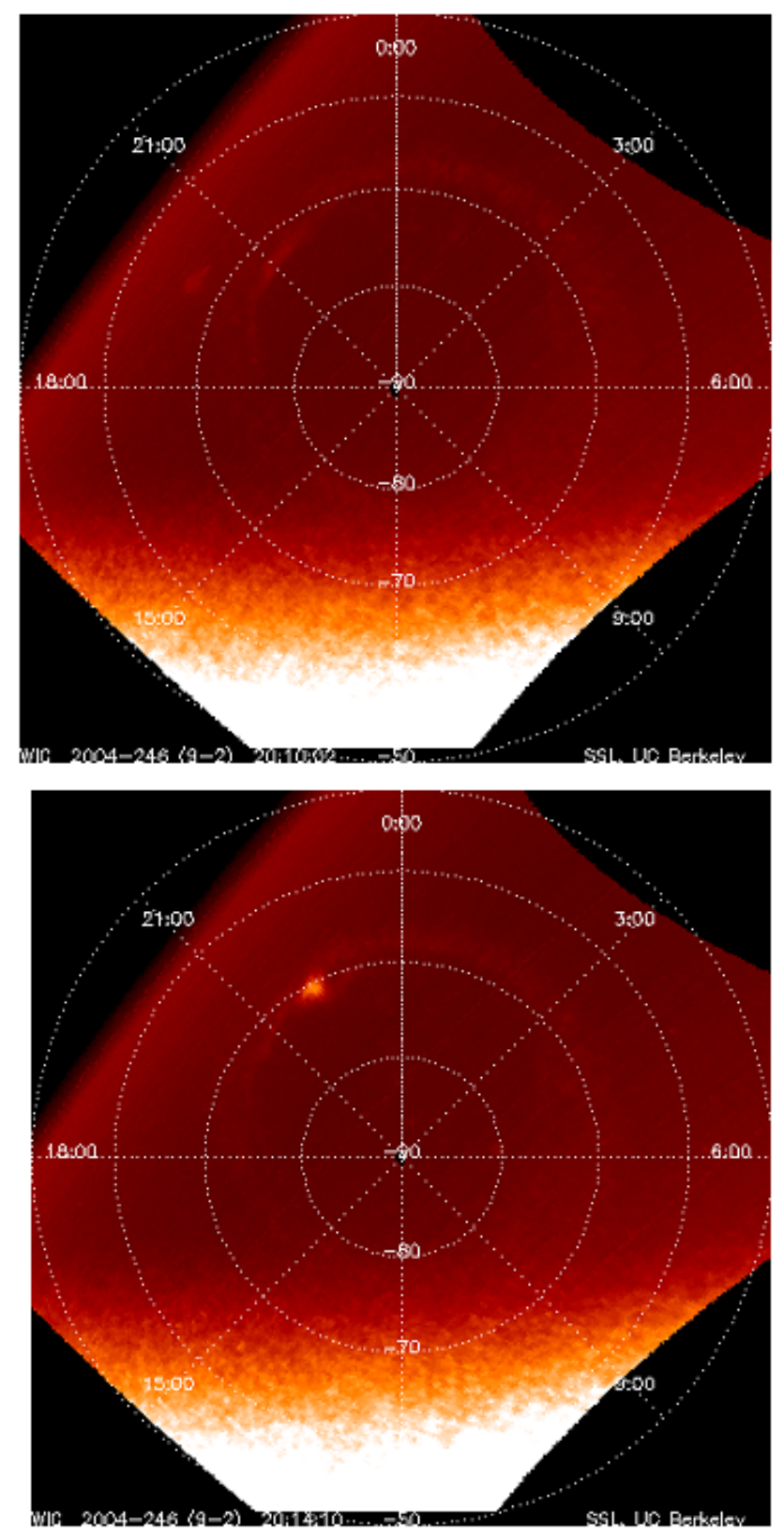

Fig. 2. Auroral images from south polar region taken by IMAGE FUV-WIC at the times 20:10:03 and 20:14:10 UT on 2 September 2004. The images are presented in the frame of MLat and MLT coordinates. The bright spot in the right frame marks the substorm onset.

ral breakup (black asterisk), and IMAGE magnetometers. The CHAMP satellite $(\sim 390-\mathrm{km}$ height $)$ had a close approach to the onset region for this event. It passed on the east side (22:18 MLT) shortly (about $0.4 \mathrm{~min}$ ) after the detection of the breakup. At onset time IMAGE magnetometers were around 21:00-23:00 MLT, ranging from $76.02^{\circ}$ to $54.16^{\circ}$ MLat, while Cluster-1 $\left(\mathrm{Xgsm}=-15.7 R_{E}\right.$, 


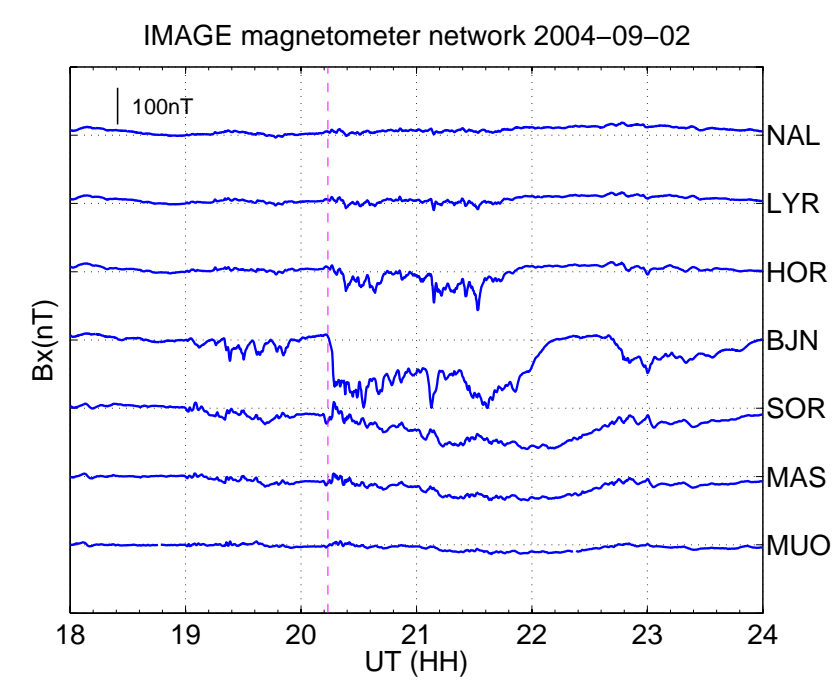

IMAGE magnetometer network 2004-09-02

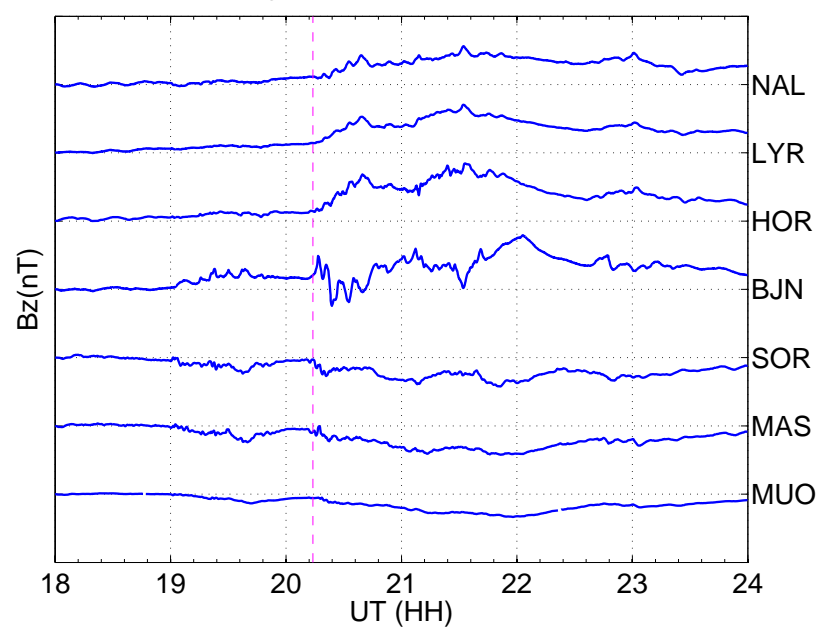

Fig. 3. Magnetograms from the International Monitor for Auroral Geomagnetic Effects (IMAGE) for the substorm under study. The red dashed line denotes the substorm onset.

Ygsm $=-2.7 R_{E}, \mathrm{Zgsm}=-3.0 R_{E}$ ) was in the post-midnight (00:25 MLT) and TC-1 $\left(\mathrm{Xgsm}=-12.3 R_{E}, \mathrm{Ygsm}=1.4 R_{E}\right.$, $\left.\mathrm{Zgsm}=-0.03 R_{E}\right)$ at the pre-midnight sector (23:57 MLT).

The auroral breakup is a sudden brightening of the auroral arcs in the midnight sector, indicating the development of a substorm (Akasofu, 1964), which can be captured well by global auroral imaging. Figure 2 shows two auroral images of the south polar ionosphere from IMAGE FUV-WIC in the frame of magnetic latitude (MLat) and magnetic local time (MLT) (Richmond, 1995). It can be seen from Fig. 2 that a prominent auroral brightening occurred at 20:14 UT (-70.12 MLat, 22:05 MLT) (Frey and Mende, 2006). In the subsequent tens of minutes (not shown) the aurora expanded azimuthally and poleward, which are typical substorm features.

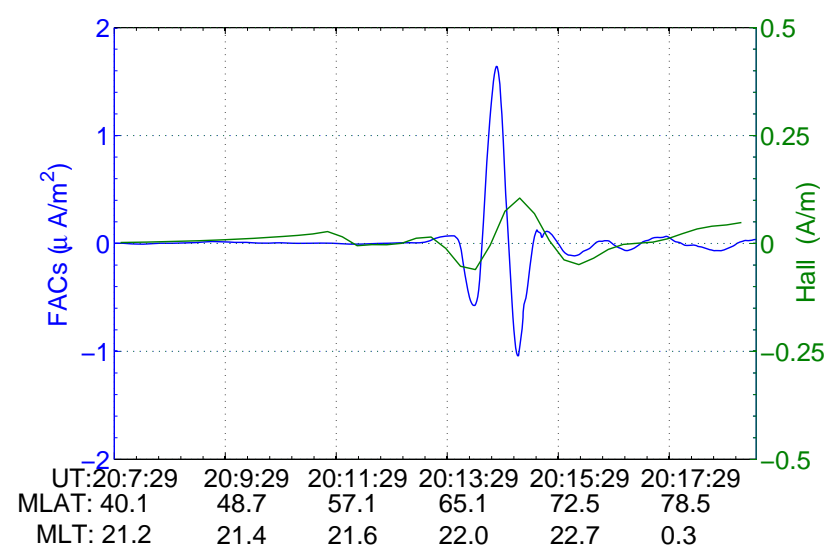

Fig. 4. Ionospheric currents observed by CHAMP at the time of the auroral breakup. Positive FACs (blue lines) are directed upward, positive Hall currents (green lines) flow westward.

Ground magnetometer recordings can exhibit typical features of substorm onset (e.g. Lühr et al., 1998). Meng and Liou (2004) mentioned that using the sharp drop in the X component of the magnetograms as substorm onset is in good agreement with auroral breakups, only if the observations happen to lie beneath the ionospheric onset location. At the time of the auroral breakup IMAGE magnetometers were located within the sector 21:00-23:00 MLT comprising the conjugate footprint region of the auroral breakup.

The magnetic field data with 10-s time resolution (see Fig. 3) provided an identical substorm onset time of 20:14 UT. It is marked by a sharp drop in the X components at the BJN station (71.28 ${ }^{\circ}$ MLat, 22:40 MLT), indicating a sudden intensification of a westward electrojet. South of it, at SOR, we find a positive X component, although less pronounced. This is indicative of a weaker eastward electrojet. In between these electrojets an upward FAC is expected. All this is consistent with the currents estimated from CHAMP magnetic field measurements (see later). The $\mathrm{Z}$ component deflection (positive downwards) was positive at stations north of BJN and negative south of BJN, implying an average location of the westward electrojet close to BJN. Although substorms are sometimes found to occur in one hemisphere and are absent in the other hemisphere (Sato et al., 1998), our observations derived from FUV imagers in the Southern Hemisphere and from ground-based magnetometers in the north show clearly that this isolated substorm occurs simultaneously and conjugately in both hemispheres.

Figure 4 shows field-aligned currents (FACs) and Hall currents (HC) derived from the magnetic field measurements on CHAMP (e.g. Wang et al., 2005a; Ritter et al., 2004), in the Northern Hemisphere shortly after the substorm onset. The Southern Hemisphere is not considered here because CHAMP passed too far from the onset region. It can be seen 


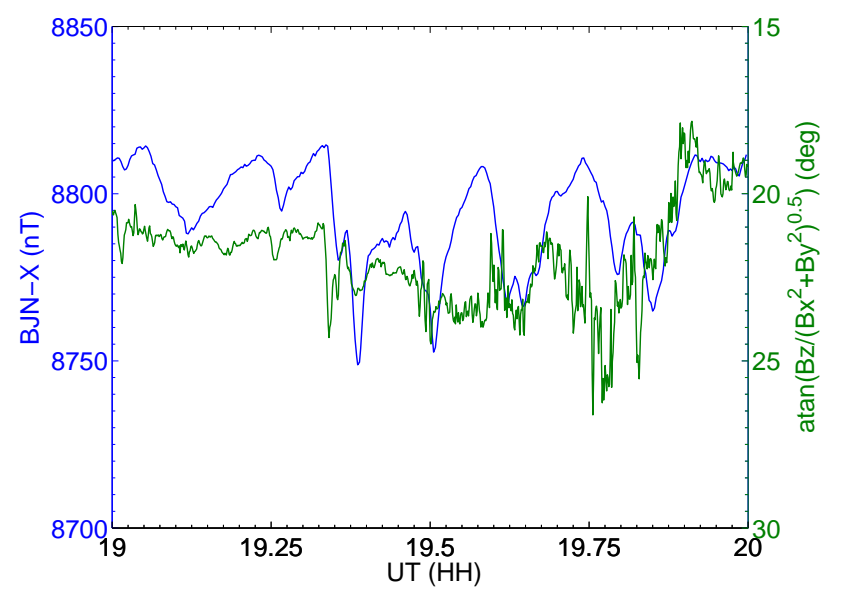

Fig. 5. X component variations observed at BJN, as well as elevation angle changes of the magnetic field at TC-1. Such signatures are typical for a pseudo-breakup. In space, features are observed about $40 \mathrm{~s}$ earlier than on the ground.

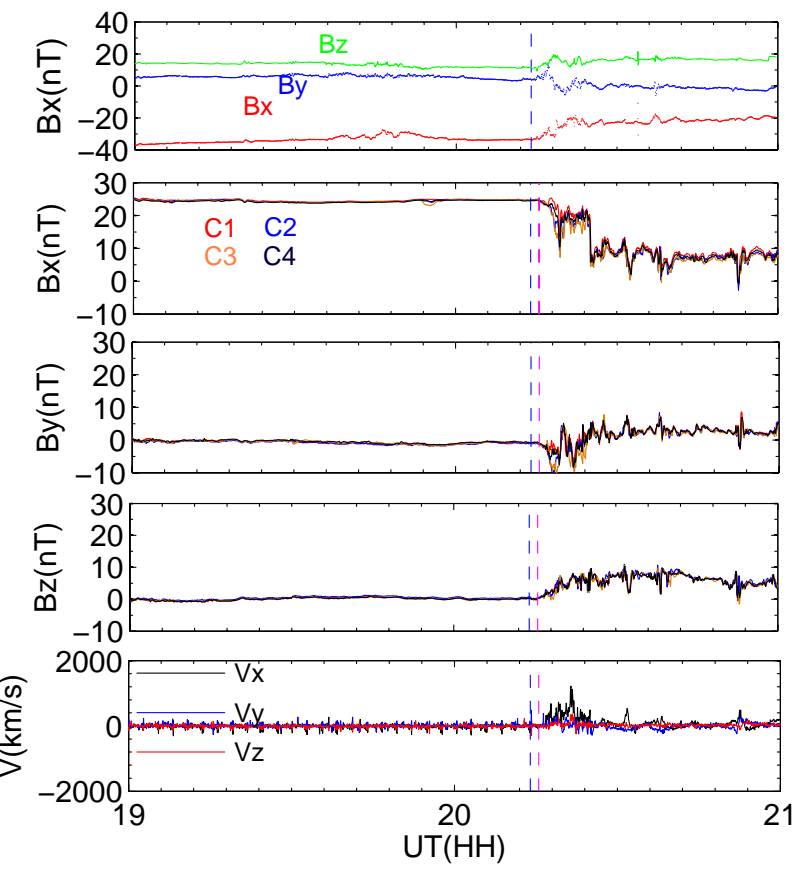

Fig. 6. Magnetotail observations of TC-1 and Cluster. In the top panel are shown $B_{x}, B_{y}, B_{z}$ in GSM coordinates observed by TC1 , below magnetic field readings of the Cluster quartet and hot ion velocity observed by Cluster-1. The vertical blue dashed line denotes the substorm onset and red, $1.44 \mathrm{~min}$ later, the time of field dipolarization at Cluster.

on Fig. 4 that the well-known, three-sheet FAC structure is observed around onset, with an intense upward FAC in the middle. The westward (positive) and eastward (negative) HC are located poleward and equatorward of the upward FAC,

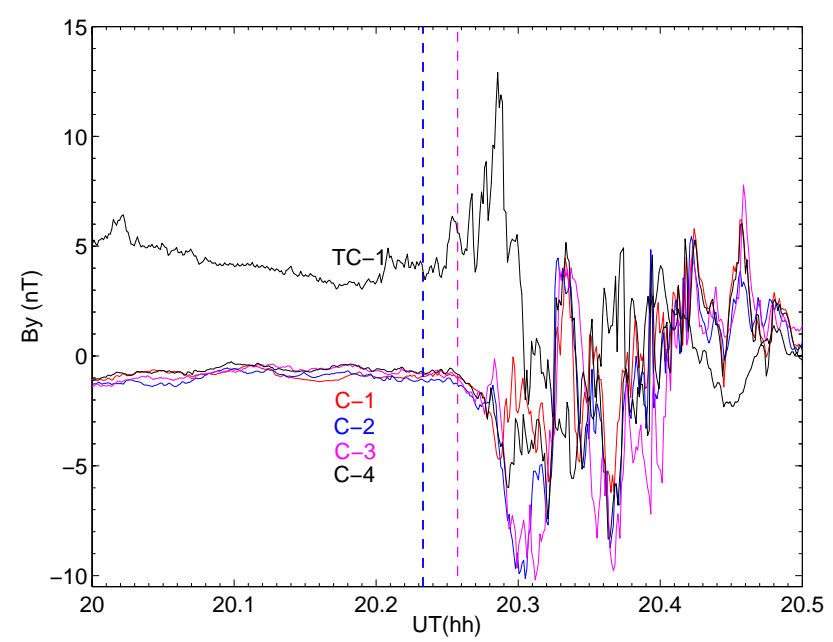

Fig. 7. TC-1 and Cluster observation of the $B_{y}$ components in GSM coordinates. The vertical dashed blue line denotes the substorm onset time and the dashed red line, $1.44 \mathrm{~min}$ later, the time of field dipolarization at Cluster.

which is typical for a Harang discontinuity. Such a current configuration is encountered quite commonly at substorm onset (e.g. Lyons et al., 2003; Wang et al., 2005b).

Before the onset, between 19:00 and 20:00 UT there is a series of pseudo-breakups visible at BJN (see Fig. 3). Pseudo-breakups are short-lived auroral breakups not followed by global expansion and significant magnetic disturbances (Akasofu, 1964). Very similar magnetic field variations were observed at TC-1. Figure 5 shows the time variations of the $\mathrm{X}$ component recorded at $\mathrm{BJN}$, together with TC-1 observations of the elevation angle, defined as $\arctan \left(B_{z} /\left(B_{x}^{2}+B_{y}^{2}\right)^{0.5}\right)$. X variations on the ground track the changes in elevation angle quite well, with a small time delay of 40 to $50 \mathrm{~s}$, indicating an earthward propagation and that TC-1 and BJN were on the same flux tube already before the onset. A similar event was studied by Lühr and Buchert (1988).

In Fig. 6 magnetotail observations are shown in the GSM coordinates from TC-1 and Cluster for the hours 19:00 to 21:00 UT. Around 20:14 UT TC-1 observed a clear magnetic dipolarization, that is, $B_{z}$ increased and $B_{x}$ decreased in intensity. TC-1 was in the Southern Hemisphere, as can be seen from the negative $B_{x}$, while Cluster was northward of the neutral sheet. The Cluster quartet observed a field dipolarization about $1.44 \mathrm{~min}$ after the auroral breakup. Almost at the same time, it recorded a fast earthward ion flow of more than $1000 \mathrm{~km} / \mathrm{s}$.

A closer inspection of the $B_{y}$ deflections reveals that intense FACs were also encountered subsequent to the dipolarization. Figure 7 shows the $B_{y}$ variations recorded both by TC-1 and Cluster. There are two things to be noted from this figure: (1) the variations are primarily in anti-phase between 
TC-1 and Cluster. Since two spacecraft sample the field in different hemispheres, the associated FACs have the same direction. (2) The variations at Cluster occurred with a delayof about $1.5 \mathrm{~min}$ with respect to TC-1. This confirms that the substorm-related FACs are also encountered with the same time delay as the dipolarization.

To characterize the propagation of the field dipolarization, we performed a timing analysis of the $B_{z}$ enhancements around 20:19 UT among the four Cluster satellites. This was done by assuming the dipolarization to be a planar front. The propagation direction and velocity of the dipolarization were determined to have mainly a dawnward component of $\sim 300 \mathrm{~km} / \mathrm{s}$, a small tailward of $\sim 4 \mathrm{~km} / \mathrm{s}$, and a northward of $\sim 140 \mathrm{~km} / \mathrm{s}$, thus suggesting that the disturbances originated duskward, earthward and southward of Cluster. Assuming the spacecraft motion is negligible and the dipolarization is moving with a constant speed, the arrival time difference of the disturbance between TC- 1 and Cluster was $\sim 1.5 \mathrm{~min}$. This is quite consistent with our observed time difference of $\sim 1.44$ min.

\section{Discussion and conclusions}

We have presented a study of both auroral and magnetotail disturbances during a well developed isolated substorm with the fortunate conjunction of a number of spacecraft and IMAGE magnetometers. Rapid changes are shown to occur in the Earth's magnetic field, ionospheric currents, and auroral displays. The substorm onset was detected at the same time, 20:14 UT, conjugately in both hemispheres. Field-aligned and Hall currents configurations, observed by CHAMP concurrently at the time of onset, are consistent with the signature of a Harang discontinuity.

TC- 1 and Cluster are not only separated in radial direction but Cluster is also eastward ( $4.1 R_{E}$ or $17^{\circ}$ in long.). The time difference of $\sim 1.44 \mathrm{~min}$ in dipolarization was found to be caused by an azimuthal expansion of the current wedge with a speed of $\sim 0.19^{\circ} / \mathrm{s}$. This is consistent with both auroral images and ground magnetometers recordings. IMAGE WIC observed that the auroral breakup occurred to the east of both spacecraft. An eastward expansion speed of $\sim 0.18^{\circ} / \mathrm{s}$ was obtained for the wedge from WIC images, which fits the timing at the spacecraft well. The substorm onset is clearly marked by a sudden decrease of $\mathrm{X}$ at BJN. The station to the north, HOR, does notice the electrojet only 7 min later. Thus, there is no evidence for a poleward jump or tailward motion of the current wedge during the early minutes after the breakup. As a consequence, the azimuthal expansion of the current wedge can explain the delays in dipolarization at the different positions. The azimuthal propagation of dipolarization is consistent with previous studies (e.g. Nakamura et al., 2005).

Besides determining the propagation of the dipolarization front we went beyond the study of Nakamura et al. (2005)
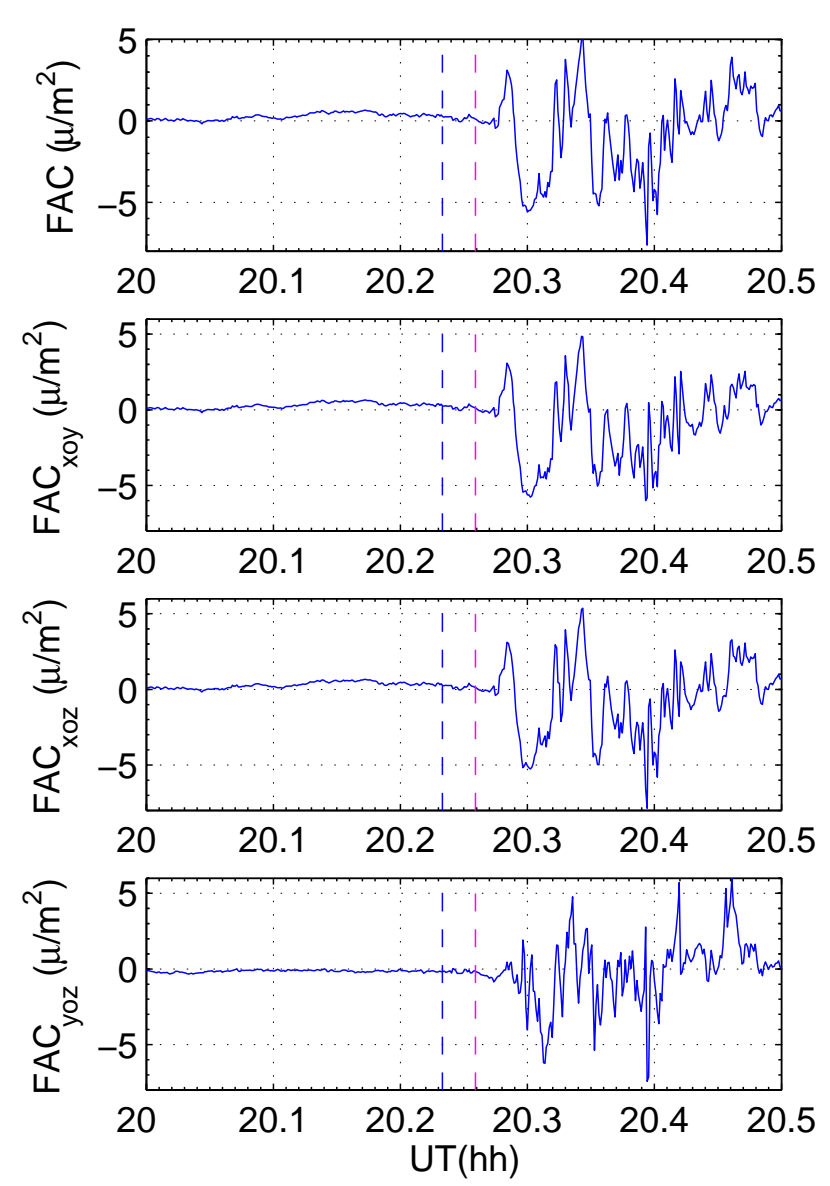

Fig. 8. Current density estimates derived from the Cluster quartet. From top to bottom are shown FACs density and current components in the GSE $x-y, x-z$ and $y-z$ planes. The vertical dashed blue line denotes the substorm onset time and the dashed red line, 1.44 min later, the time of field dipolarization at Cluster.

and examined to which part of the current wedge the various spacecraft were connected. For this purpose we looked at the field-aligned currents following around the substorm onset. The CHAMP observations at low orbit showed a dominant upward FAC in the vicinity of the onset location. This upward current can be associated with the auroral breakup observed by IMAGE-WIC. When mapped into the magnetosphere this FAC at the duskward end of the current wedge should flow tailward in both hemispheres. We have employed magnetic field data of the Cluster quartet to determine the current density vector by using the curlometer technique. Figure 8 shows, in the top panel, the derived FAC density and below, the three components of the current vector. Following the onset, Cluster encountered first briefly an earthward flowing FAC (positive values), but was then embedded for a substantial time period in tailward FACs (negative values). As mentioned before, TC-1, located in the other hemisphere, observed By variations in anti-phase with Cluster. This means 
both spacecraft sensed predominantly tailward FACs. From that we conclude that the ground stations and all the satellites observed the duskward part of the current wedge. Thus, it is justified to interpret the time delays in terms of azimuthal propagation. Also, IMAGE-WIC data confirm the azimuthal expansion of the auroral arc extending from 22:05 MLT to 23:30 MLT in 2 min.

Our initial aim was to make use of the multi-spacecraft configuration to find arguments for any of the competing substorm onset models. This could not be achieved by this case study. However, some preferences for the one or other model may be deduced. TC1 observed field turbulence at auroral breakup time. This may be interpreted as turbulence in support of the CCI model. However, TC-1 plasma flow measurements are not available for this event. From that one could tell whether the magnetic field fluctuations are caused by the braking of the earthward bursty bulk flows or by cross-tail current disruption itself, as predicted by the NENL or CCD models.

The presented event shows that the field dipolarization expands mainly azimuthally during the first few minutes, which exhibits a large current wedge with a radial extent of more than $4 R_{E}$ and several hours in longitude. This may be another class of substorm that is different from CCD and NENL models. However, to test the before mentioned casual relationship of substorm onsets, more case studies are needed with spacecraft near the current sheet at various radial distances. More substorm events have to be considered to find out the statistical significance of our new class.

Acknowledgements. We thank ACE and IMAGE teams for providing data. The Cluster and Double Star teams are greatly acknowledged for satellite operation and data processing. The operational and data processing supports of the CHAMP mission by the German DLR and BMBF are gratefully appreciated. This study is also supported by the National Nature Science Foundation of China (No. 40390150, No. 40604017, and No. 40504019).

Topical Editor I. A. Daglis thanks L. Lyons, A. Lui and another referee for their help in evaluating this paper.

\section{References}

Akasofu, S. I.: The development of the auroral substorms, Planet. Space. Sci., 12, 273-282, 1964.

Baker, D. N., Pulkkinen, T. I., Angelopoulos, V., Baumjohann, W., and McPherron, R. L.: Neutral line model of substorms: Past results and present view, J. Geophys. Res., 101, 12 975-13010, 1996.

Birn, J., Hesse, M., Haerendel, G., Baumjohann, W., and Shiokawa, K.: Flow braking and the substorm current wedge, J. Geophys. Res., 104, 19 895-19904, 1999.

Frey, H. U. and Mende, S. B.: Substorm onset observed by IMAGEFUV: 2003-2005, J. Geophy. Res., in print, 2006.
Lühr, H. and Buchert, S.: Observational evidence for a link between currents in the geotail and in the auroral ionosphere, Ann. Geophys., 6, 169-175, 1988, http://www.ann-geophys.net/6/169/1988/.

Lühr, H., Aylward, A., Bucher, S. C., Pajunpää, A., Pajunpää, K., Holmboe, T., and Zalewski, S. M.: Westward moving dynamic substorm features observed with the IMAGE magnetometer network and other ground-based instruments, Ann. Geophys., 16, 425-440, 1998, http://www.ann-geophys.net/16/425/1998/.

Liou, K., Meng, C. I., Lui, A. T. Y., Newell, P. T., and Wing, S.: Magnetic dipolarization with substorm expansion onset, J. Geophys. Res., 107, 1131, doi:1029/2001JA000179, 2002.

Liu, Z. X., Escoubet, C. P., Pu, Y. Z., Laakso, H., Shi, J. K., Shen, C., and Hapgood, M.: The Double Star mission, Ann. Geophys., 23, 2707-2712, 2005, http://www.ann-geophys.net/23/2707/2005/.

Lui, A. T. Y.: Current disruption in the Earth's magnetosphere: Observations and models, J. Geophys. Res., 101, 13 067-13088, 1996.

Lyons, L. R.: Substorms: Fundamental observational features, distinction from other disturbances, and external triggering, J. Geophys. Res., 101, 13 011-13026, 1996.

Lyons, L. R., Wang, C.-P., and Nagai, T.: Substorm onset by plasma sheet divergence, J. Geophys. Res., 108, doi:10.1029/2003JA010178, 2003.

Meng, C. I. and Liou, K.: Substorm timings and timescales: A new aspect, Space Science Review, 113, 41-75, 2004.

Nakamura, R., Baumjohann, W., Zhang, T. L., Carr, C. M., Balogh, A., Fornacon, K.-H., Georgescu, E., Réme, H., Dandouras, I., Takada, T., Volwerk, M., Asano, Y., Runov, A., Eichelberger, H., Klecker, B., Mouikis, C., Kistler, L. M., and Amm, O.: Cluster and Double Star observations of dipolarization, Ann. Geophys., 23, 2915-2920, 2005, http://www.ann-geophys.net/23/2915/2005/.

Richmond, A. D.: Ionospheric Electrodynamics Using Magnetic Apex Coordinates, J. Geomagn. Geoelectr., 47, 191-212, 1995.

Ritter, P., Lühr, H., Viljanen, A., Amm, O., Pulkkinen, A., and Sillanpää, I.: Ionospheric currents estimated simultaneously from CHAMP satellite and IMAGE ground-based magnetic field measurements: A statistical study at auroral latitudes, Ann. Geophys., 22, 417-430, 2004, http://www.ann-geophys.net/22/417/2004/.

Sato, N., Nagaoka, T., Hashimoto, K., and Saemundsson, T.: Conjugacy of isolated auroral arcs and nonconjugate auroral breakups, J. Geophys. Res., 103, 11 641-11 652, 1998.

Shiokawa, K., Baumjohann, W., Haerendel, G., Paschmann, G., Fennell, J. F., Friis-Christensen, E., Lühr, H., Reeves, G. D., Russel, C. T., Sutcliffe, P. R., and Takahashi, K.: High-speed ion flow, substrom current wedge, and multiple Pi2 pulsations, J. Geophys. Res., 103, 4491-4507, 1998.

Wang, H., Lühr, H., and Ma, S. Y.: Solar zenith angle and merging electric field control of field-aligned currents: A statistical study of the southern hemisphere, J. Geophys. Res., 110, doi:10.1029/2004JA010530, 2005a.

Wang, H., Lühr, H., Ma, S. Y., and Ritter, P.: Statistical study of the substorm onset: its dependence on solar wind parameters and solar illumination, Ann. Geophys., 23, 2069-2079, 2005b. 